\title{
Toward Understanding Social Media Marketing's Possitive And Negative Sides From Literature Review Perspective
}

\author{
Dinara Adilova \\ School of Management, Shanghai University 99 Shangda Street, Baoshan District, Shanghai, 200444, China
}

\begin{abstract}
Social media has become an important new cultural and social phenomenon, changing the way millions of people and businesses connect and communicate. Today, social media has become omnipresent and most essential for social networking, content sharing and online accessing. Due to its wide spread and instantaneous features, social media opens a wide place for businesses such as online marketing. Marketing which occurs via social media is known as social media marketing. Social media marketing has made possible for companies to reach targeted consumers easily, effectively and instantly. Besides that, social media marketing also faces several challenges in the field. This article argues on social media marketing's advantages and disadvantages in recent days and refers deeply the most important features of them.
\end{abstract}

Keywords: social media marketing, phenomenon, WOM, social media platforms, Facebook, social interaction, user-generated content.

\section{Introduction}

The existance of Internet-based social media has made it possible for one person to contact with hundreds or even thousands of people around the world. Social media has exploded as a category of online discussion where people create content, share it, bookmark it and network at vast rate. All types of social media provide an opportunity to present oneself and one's products to dynamic communities and individuals that may be interested (Roberts \& Kraynak 2008). Social media includes a variety of applications that, using technical terms, allow consumers to "post", "tag", "digg", "blog", and etc. This content created by social media is a type of newly generated resource for online information that is created, spread, and used by consumers desiring to educate each other about products, brands, services, and problems (Xiang \& Gretzel 2010). Examples include Facebook, Instagram, Twitter, LinkedIn. Due to its ease way of use, speed and reach, social media became the trendsetter in topics that range from environment, politics, and technology to entertainment industry. Social media are essentially self-promoting in that users spread. The viral quality of social media makes it an appealing tool for businesses to market products and services (Xiang \& Gretzel 2010). Social media is evolving phenomenon in marketing. Marketers are beginning to aware the use of social media as a component in their marketing strategies and campaigns to reach out to customers. Promotions, marketing intelligence, sentiment research, public relations, marketing communications, and product and customer management are subdisciplines of marketing that may use social media (Tanuri, 2010). Each social media platform (such as blogs, online discussion forums, and online communities) has an effect on marketing performance (e.g., sales), so it is vital to understand their relative importance and their interrelatedness (Stephen \& Galak 2009).

Furthermore, users of social media now are highly motivated customers. As exposed by Nielsen's (2011), State of the Media: Social Media reports that 70\% of social media users are engaged in online shopping (Nielsen, 2011). Consumers easily get what they want just by sitting in front of computer screen and accessing online websites. Though social media marketing has huge benefits on consumers and marketers, at the same time it has negative impacts on both of them. Due to its ease way of getting access to information, lack of monitoring and control, undoubtedly it favors many risks and cyber crimes. In the coming chapters we will be discussing about advantages and disadvantages of social media marketing in further detail.

\section{Social Media Marketing and Its features}

Social media marketing is a growing way in which businesses are reaching out to targeted customers easily. Social media marketing can be simply defined as the use of social media channels to promote a company and its products. This kind of marketing can be thought of as a subset of online marketing activities that complete traditional Web-based promotion strategies, such as e-mail newsletters and online advertising campaigns (Barefoot \& Szabo 2010). By encouraging users to spread messages to personal contacts, social media marketing has injected a new term of exponential dissemination and trust to mass communication and mass marketing (Hafele, 2011). By this new approach of outreach and marketing, new instruments are being developed and increased in turn for businesses. Social media marketers are now going better and more effective insight through the introduction of analytic applications by official social network site platforms (Hafele, 2011). There are several most popular social media platforms which comes to mimd, and they take many different 
forms and contain different features. Undoubtedly, the most common social media platform is Facebook. Facebook was first launched in February 2004, owned and operated by Facebook, Inc. As of May 2012; Facebook has over 900 million active users. Users must register before using the site; they may create a personal profile, add other users as friends, and exchange messages, including automatic notifications when they update their profile (Facebook, 2012). In addition, users may join common-interest user groups; categorize their friends into lists such as "People From Work" or "Close Friends". Facebook ${ }^{\text {ee }}$ main mission is to give people the power to share and make the world more open and connected (Facebook, 2012). Nowadays, new function on Facebook was added, and more advertisment appears on this website.

Other social media platforms such as Twitter, Google plus, and LinkedIn may differ in some ways, but essentially they work using the same principles. Marketing using social media to spread information fastly and easily among huge auditory of users and potential customers. The traditional Facebook model, in particular, involves replacing the concept of a human "friend" with a brand or tangible product or creating a page or group (Facebook, 2011). A user who elects to "like" a product or company advertises that connection to their own private network of contacts. This concept extends to other forms of social media as well. According to Bernie Borges (2009), Twitter is combination of micro blogging and social network (Borges, 2009). Twitter, allows users to receive small updates and advertisements from favored producers as well (Hafele, 2011). Twitter gives opportunity to users to involve in real time sharing. A tweet is usually no more than 140 characters, which followers of the user can see (Borges, 2009).

These two social media platforms are among the most popular and heavily used options now, but they are far from being the only ones. As observed by Kaplan and Haenlein (2010) cited by Nick Hafele (2011) have identified several channels that fall under the category of social media, each of which has opportunities and unique advantages for marketing use. Collaborative projects, such as wikis, or editable data-sources, are particularly poignant avenues of contact. In fact, trends indicate that they are quickly becoming the predominant source of information among consumer populations (Kaplan \& Haenlein, 2010) cited by (Hafele, 2011).

Blogs, managed by either individuals or organizations, are another heavily used marketing forum. Through blogs, businesses can promote brand awareness by sharing insider information, updating customers on new products, as well as providing links to the main sales channels. Fans will be updated time to time on any special events, contests or a new promotion organized by the brand or product. Blogs also facilitate the posting of comments and feedbacks, allowing fans and detractors to post opinions and questions to producers. This encourages the exchange of ideas between peers and can also promote honest discussion between individuals and companies to improve their defaults (Hafele, 2011). Social media approaches need to be considered to ensure the highest chance of success with a social media marketing. According to Ray et al. (2011) cited by Nick Hafele (2011) emphasize the need for diversifying a social media strategy to ensure that messages are reaching appropriate audiences; there is no single correct approach.

\section{Word of Mouth}

Social media associate eWOM with online consumer-to-consumer interactions about brands (Muntinga et al., 2011). Research shows that eWOM has higher credibility, empathy, and relevance for cus- tomers than marketer-created sources of information on the Web (Gruen, Osmonbekov, \& Czaplewski, 2006). Social media are ideal tools for eWOM, because consumers generate and spread brand- related information to their friends, peers, and other acquaintances without constraints (Kim \& Ko, 2012; Vollmer \& Precourt, 2008). Jansen, Zhang, Sobel, and Chowdury (2009) study examine the WOM activity regarding brands on Twitter. They find that consumers' posts generate information dissemination processes, which include branding comments, sentiments, and opinions.

According to Chu and Kim (2011), researchers can examine the use of eWOM on social media from three perspectives: opinion seeking, opinion giving, and opinion passing. Consumers with a high level of opinion seeking behavior tend to search for information and advice from other consumers when making a purchase decision. Consumers with a high level of opinion-giving behavior, also called opinion leaders, have a significant influence on consumers' attitudes and behaviors. Finally, online forwarding is a specific characteristic of eWOM that facilitates the flow of information. The discussion in this paper therefore refers to WOM as the extent to which consumers of luxury brands pass along information and upload content on social media.

\section{Advantages}

According to Watson et al. (2002) cited by Sheth and Sharma (2005) with the popularity of digital marketing on the rise, many businesses are investigating how social media can help them promote their products and services to potential and existing customers. Social networking sites like Facebook and Twitter have transformed the way some businesses think about advertising. Some businesses direct customers toward their social network pages more than they direct them to their own websites. There are certain advantages to market 
via social media, but there are also related drawbacks as well (Watson et al. 2002; Sheth \& Sharma 2005).

The primary advantages of social media marketing is reducing costs and enhancing reach. The cost of a social media platform is typically lower than other marketing platforms such as face-to-face sales people or middlemen or distributors. In addition, social media marketing allows firms to reach customers that may not be accessible due to temporal and locational limitations of existing distribution channels. Social media platforms increase reach and reduce costs by providing three areas of advantage for customers (Watson et al. 2002; Sheth \& Sharma 2005).

First, the marketing firm can provide unlimited information to customers without human intervention. This is an advantage over other forms of contact because the amount of information that can be provided is much greater than in any other form of communication. Additionally, and more importantly, the information can be provided in a form that customers can easily process and understand. For example, airline scheduling and reservation systems are very difficult to create and maintain to serve individual needs. Additionally, in this context, the choices are large and difficult to provide in any format that is better than web-based format (Watson et al. 2002; Sheth \& Sharma 2005).

Second, social media marketing firm can create interactions by customizing information for individual customers that allow customers to design products and services that meet their specific requirements For example, online checking and seat assignment can be done on the Internet. Finally, social media platforms can allow transactions between customers and firms that would typically require human contact as in the case of successful firms such as Dell and amazon.com (Watson et al. 2002; Sheth \& Sharma 2005).

To understand better about the advantages of social media marketing, there are five main advantages to succeed in this field:

\section{1) Cost-related}

According to Weinberg (2009), The main advantage of social media marketing is cost-related. The financial barriers to social media marketing are quite low compared to others. The majority of social media sites are free to access, create profile and post information. Whereas traditional marketing campaigns can cost millions of dollars, many social media tools are free even for business use. Businesses can run highly successful social media marketing campaigns on a limited budget. The advantage of reaching your targeted market for little or no cash investment is substantial, and the audience wanting your information voluntarily joins or follows you. Pay-per-click advertisements on sites such as Facebook are "geo-targeted" according to specific criteria, to reach the correct audience. The viral nature of social media means that each person who reads your posts has the capability to spread the news farther within his own network, so information can reach a large number of people in a short time (Weinberg, 2009).

\section{2) Social Interaction}

One of the most notable phenomena of new media is how it has increased and created new forms of social interaction. People spend more than a quarter of their time online involved in communication activities (e.g., emails, IM chat, and social networks), which is equivalent to the total time spent online for general leisure and entertainment (Riegner, 2007) cited by (Hill \& Moran, 2011). Social networking sites have become so pervasive that they are the most popular Internet destinations (Burmaster, 2009). Not only has new media demonstrably altered how often people communicate online, but it has also enlarged the pool of individuals they communicate with, and led to new ways for behaviors to be influenced (Burmaster, 2009). Consumer behavior studies reveal that individuals give greater consideration to advice and information shared online, spending more time with websites that provide third-party evaluations (Huang et al. 2009), and other studies indicate such information can directly influence buying decisions, even if received from purely ,virtuale sources (Awad et al. 2006; Weiss et al. 2008) cited by (Hafele, 2011). Indeed many of the reported benefits of new media usage (increased reputation, anticipated reciprocity) relate directly to its social interaction aspects (Kollock 1999; Arthur et al. 2006) cited by (Hafele, 2011).

\section{3) Interactivity}

As observed by Steuer (1992) cited by Ronald P. Hill and Nora Moran (2011) unlike watching TV or listening to the radio, the interactivity of new media lets consumers become more than just passive recipients of stimulation. Interactivity can be broadly described as the "extent" to which users participate in modifying the form and content of a mediated environment in real time (Steuer, 1992). Interactivity is one of the defining characteristics of new media technologies, giving greater access to information as well as supporting increased user control of and engagement with social media content (Fiore et al. 2005) cited by (Hill \& Moran, 2011). Interactivity depends on the context. In an online social networking context, interactivity refers to a usercentered interaction with machines, messages, or other users, focusing on the experiential aspect of networking process (Liu \& Shrum 2002) cited by (Hill \& Moran, 2011). 
While interactivity can be simple in certain contexts (e.g., simply filling out forms, clicking links), it can also be more involved and elaborate, such as allowing individuals to develop online content (Murugesan, 2007) cited by (Hill \& Moran, 2011). Studies show that increased levels of interactivity can lead to higher involvement (Bucy, 2003) and more positive attitudes toward websites (Kalyanaraman \& Sundar, 2003; Hill \& Moran, 2011) along with higher source credibility (Fogg, 2003; Hill \& Moran, 2011).

This user interactivity enables consumers to participate in personal social networking by selecting the content, timing, and communication act Specific applications of social media empower consumers, such that they can take active control and perform two-way communications. Active control takes place in a social networking context and requires attention and participation from all participating parties, including individual users, groups of networked people or communities, and brands (Li, Daugherty, \& Biocca 2002).

\section{4) Targeted market}

Social media provide marketers with the ability to target audiences and consumers based on site users' personal interests and what their friends like. For example, list country music as one of your interests on a social networking site; you will most likely be seeing ads about country music concerts and artists. Some sites' advertising will also highlight which country artists your friends like to provide a personal connection. With such "smart" marketing, and advertising, marketers effectively reach the people who are most interested in what they have to offer. Furthermore, social networking enables word of mouth to promote products beyond what advertising alone does (Hill, Provost \& Volinsky, 2006).

A well-cited example of viral marketing combines network targeting market and implicit advocacy: The Hotmail free e-mail service appended to the bottom of every outgoing e-mail message the hyperlinked advertisement, "Get your free e-mail at Hotmail," thereby targeting the social neighbors of every current user while taking advantage of the user"s implicit advocacy (Montgomery, 2001). Traditional marketing methods do not appeal to some segments of consumers. Some consumers apparently value the appearance of being on the cutting edge or "in the know," and therefore derive satisfaction from promoting new, exciting products (Hill, Provost \& Volinsky 2006).

\section{5) Customer Service}

Customer service is another crucial area for social media marketing (Helmsley, 2000). Sometimes website designers cannot avoid a certain degree of complexity in the architecture of a website. Therefore, it is necessary to have a thoughtful customer service system. Links to Frequently Asked Questions (FAQs) and links to online representatives are useful in order to assist customers in the selection or buying process. A marketer should not just offer online assistance. In many cases, it is more convenient for customers to call a company. Therefore, the use of a toll free phone number for customers should be considered (Gommans et al., 2001).

According to Gommans et al. (2001), Order fulfillment and rapid delivery systems are as critical to eloyalty development as the other factors. A thoughtful logistics system that guarantees a fast delivery after the checkout process contributes to customer satisfaction, which in turn contributes to loyal behavior. In addition to the speed of delivery, the logistics system should allow different ways of delivering products. Some customers prefer to get the product delivered by parcel services, like FedEx and UPS. Others might want to pick up a product in a physical store in order to have somebody to talk to (Gommans et al., 2001).

A customer who buys something on the Internet has one major disadvantage compared to a customer in real space. Internet customers cannot touch, smell, or experience the good before they buy it. This makes a shopper insecure about buying a product. In order to minimize this insecurity, an social media marketers should offer brands that are well-known, good product quality, and, of course, guarantees (Gommans et al., 2001).

\section{Disadvantages}

The online environment creates not only opportunities, but also complications and challenges for the social media marketing process. The transparency of the web makes online information available to all audiences, and reinforces the need for consistency in the planning, design, implementation and control of online marketing communication (Hart et al., 2000).

There are five main disadvantages need to be considered on social media marketing, which are:

1) Time intensive

As the name implies, social media is interactive, and successful, two-way exchanges take commitment. The nature of marketing changes in social networks, with the focus placed on establishing long-term relationships that can turn into more sales. Somebody has to be responsible to monitor each network, respond to comments, answer questions and post without a service to manage these social networks will find it difficult to compete. The first preliminary consideration and probably the most important one is that social media marketing requires a significant time investment (Barefoot \& Szabo, 2010). As a general rule, simply dabbling in a few 
social media resources and hoping to realize enormous returns is fanciful. A company must realize the necessary time commitment and either accept or reject that commitment as plausible for its operation (Barefoot \& Szaboo, 2010).

\section{2) Trademark and Copyright Issues}

According to Steinman and Hawkins (2010), It is of the utmost importance for companies to protect their own trademarks and copyrights when using social media to promote their brands and products. A company's brands and other intellectual property are often nearly as valuable as the products or services that they offer. Social media's capacity to facilitate informal and impromptu communication often on a real time basis can aid companies in promoting their brands and disseminating copyrighted material, but it can also facilitate third party abuse of a business's trademarks and copyrights (Steinman \& Hawkins, 2010).

When using social media, whether via a third-party outlet or a company's own social media platforms, marketers should regularly monitor the use of their trademarks and copyrights. Companies should monitor their own social media outlets as well as third-party social media platforms to ensure that those providing content through the media outlets are not misusing their intellectual property. Internet tracking and screening services are available to monitor the use of your business's marks and copyrights on third-party sites, including checking social media sites for profile or user names that are identical or substantially similar to your company's name or brands (Steinman \& Hawkins, 2010).

As stated by Steinman and Hawkins (2010), This form of business impersonation can damage a company's brand and reputation if left unchecked; such monitoring can also serve as a positive indicator of business success. Companies should consider reserving, on various social media sites, user names that match or closely resemble their trade names and marks (Steinman \& Hawkins, 2010).

In addition, companies should have terms and conditions for their own social media outlets, with provisions specifying how to properly use the companies or third-party intellectual property. Marketers conducting certain types of social media marketing campaigns, particularly promotions and user-generated content campaigns, should have rules in place that include specific prohibitions regarding trademark and copyright infringement and impersonation (Steinman \& Hawkins, 2010).

\section{3) Trust, Privacy and Security Issues}

Using social media to promote one's brand, products, or services can also implicate trust, privacy and data security issues. It is important for companies to understand these issues and takes conforming measures to minimize their exposure to liability related to personal data collection, use, and maintenance. Trust, particularly the unique dimension of transactional security and privacy (Hoffmann et al., 1999), play a critical role in generating customer loyalty to social media marketers. A study by Ratnasingham (1998) has shown that fear of online credit card fraud has been one of the major reasons customers have not done more extensive online buying (Ratnasigham, 1998). Moreover, privacy concerns have led to a public relations fiasco for some major social media marketing resulting in substantial brand image erosion (Advertising Age, 2000). Social media companies like Facebook and Twitter generally have their own privacy policies that govern their use of consumer data and third-party conduct on the social media platform with respect to personal data. Marketers using third-party social media outlets should ensure that their marketing campaigns do not encourage consumers or any other parties to engage in practices that would violate the social media company's privacy policy, and marketers should also ensure that they are abiding by the policies as well. Companies that administer their own blogs or other social media platforms should also maintain comprehensive policies that disclose the company's data collection, use, and storage practices, and any responsibilities that third parties have regarding privacy and data security (Steinman \& Hawkins, 2010). Trust, which is closely related to security, is a very important factor in the online buying process behavior process. In general, you cannot feel, smell, or touch the product. You cannot look into the salesperson's eyes (Steinman \& Hawkins, 2010). Therefore, these ways of developing trust are excluded on the Internet. Brand trust usually contributes to a reduction of uncertainty. In addition, trust is a component of the attitudinal component of loyalty. So it is obvious that loyalty in general and brand trust in particular can help to overcome some of the Internet's disadvantages, e.g. to overcome perceptions that the Internet is an unsafe, dishonest, and unreliable marketplace. In fact, these perceptions are still stopping some potential customers from doing business on the web. A "third party approval" is a tool to generate trust (Gommans et al. 2001).

\section{4) User-Generated Content (UGC)}

During last years, users have spent more time and shared more information, thoughts, and opinions with each other easily via the Internet. Also, new forms of content generation, communication, and collaboration have come out on the Internet. Oftentimes marketing strategies involving social networking sites or other social media incorporate user-generated content (UGC) into the field (Filho \& Tan 2009). For example, UGC allows 
Internet users to make comments in various forms, such as photos, videos, podcasts, ratings, reviews, articles, and blogs (Filho \& Tan 2009). Whether it"s a video or photo shared on a site or messages that site users disseminate to members of the network, UGC holds much promise as a marketing tool. In addition, usergenerated content comes with a relatively high degree of credibility in the eyes of consumers, particularly if someone created the content for example or a tweet between friends. Soliciting user-generated content in connection with a marketing strategy comes with some risk of incurring legal liability for content created by an individual participating in the campaign Marketers can, however, take certain steps to minimize legal risks associated with marketing campaigns that involve the dissemination of user-generated content through social media (Gommans et al. 2001).

\section{5) Negative WOM}

Social media, in a way, converts consumers into marketers and advertisers, and consumers can create positive or negative pressure for the company, its products, and its services, depending both on how the company is presented online and on the quality of products and services presented to the customer (Roberts \& Kraynak 2008). Consumer-generated product reviews, images, and tags, which serve as a valuable source of information for customers making product choices online (Ghose, Ipeirotis, \& Li 2009), have increased rapidly on the Internet and have had a great impact on electronic commerce (Forman, Ghose, \& Wiesenfeld 2008) following the emergence of Web 2.0 technologies.

One aspect of social networking that is especially damaging to marketing campaigns is negative post responses. Unhappy customers or industry competitors are able to post disparaging or offensive pictures, posts or videos and there is not much a marketer can do to prevent these occurrences (Cheung, Lee, \& Thadani 2009). Still, negative or other non-constructive feedback cannot be ignored. Social networks must be managed efficiently enough to immediately respond and neutralize harmful posts, which takes more time (HennigThurau et al. 2004).

\section{Discussion}

Academic researchers and practitioners in marketing are showing substantial interest in this new form of communication, trying to understand the challenges and opportunities associated with social media. According to Jim Davis, Sr., Vice President and CMO of SAS, "just a few years ago, we were talking about the information revolution - today, we are witnessing a social media revolution. Social media has also become a major focus in corporate marketing strategy. According to the 2014 Social Media Industry Report (Stelzner 2014), 97\% of companies are using some form of social media to market their business. Moreover, the advent of social media has opened up new opportunities for brands to connect with consumers. A majority of companies now include social media in their communication strategy.

According to Gurau (2008), The online marketing environment raises a series of opportunities and also challenges for social media marketing practitioners. The audiences become more fragmented and proactive, but on the other hand, the company has the possibility to combine various modes and categories of information in a complex message. Social media also permit the enterprises to collect, register, analyze and use customer data and feedback for better targeting online audiences and customizing its messages (Gurau, 2008). In fact, the specific characteristics of the Internet and social media applications are making the implementation of integrated online marketing both inevitable and efficient for an online approach. The cost-related factors, social interactions, interactivity, targeted market opportunities, and customer services are excellent features for organizations to adopt a proactive-reactive attitude and to succeed in social media marketing. On the other hand, downside of social media marketing such as time intensive, trademark and copyright issues, trust, privacy and security issues, user-generated content (UGC) and negative feedbacks from customers are major barriers facing by social media marketers (Gurau, 2008).

Designing and implementing a specific model of integrated social media marketing can integrate these characteristics. The message communicated online should be first infused with the core corporate values, then adapted to the online strategy and tactics of the organization, and finally customized for a specific combination of targeted audience and online channel. The selection of the appropriate communication-mix needs to take into account the characteristics of social media marketing (Gurau, 2008).

\section{Conclusion}

Social media can be established anywhere with an Internet connection, and it should be considered by marketers, advertisers, and online content creators as a basic part of their communications because social media affects all aspects of the Internet and transforms the role of Internet in people se lives (Universal McCann 2008).

Today, consumers gain a new role with social media. Consumers are becoming "content creators" and thus, functional consumers instead of just consuming, as in the past. Social media applications or tools that facilitate this are blogs, micro blogging applications (such as Twitter), social networking sites (such as 
Facebook), podcasts, video and photo sharing sites (such as YouTube and Flickr). Given this reality, it is useful for companies, especially marketers to integrate social media into marketing and their marketing strategies.

This study has attempted to identify the major advantages and disadvantages determined by the development of Internet technology in the area of social media marketing. Social media is the modern tool for marketers who try every means to get their message out to their target markets. The medium has many advantages and disadvantages based on their firm, and many companies still struggle to find the right way to use it. The average business owners or marketers do not fully understand the risks and challenges in it. The field is still so fresh that it is difficult to evaluate the qualifications of social media "experts" who offer their services online. So, before a company step into the field of social media marketing, they have to complete full research on social media practices. An organization has to master basic principles and tactics of using social media as an effective tool in order to survive in the field of social media marketing. Main goals of a company or organization have to engage customers, to protect company reputation, to provide customers with good quality of product and services and to satisfy customer"s need.

\section{References}

[1]. Advertising Age "Crisis RX for Double Click." (2000). Advertising Age, 71 (9): 58

[2]. Arthur, d., Sherman, C., Appel, d. \& Moore, L. (2006). "Why young consumers adopt interactive technologies. Young Consumers", 7(3), pp. 35-38

[3]. Awad, N.f., Dellarocas, C. \& Zhang, X. (2006). "The digital divide of word of mouth. Proceedings of the first Midwest united States Association for Information Systems", Grand Rapids, MI (May 5-6).

[4]. Barefoot, D., and J. Szabo. (2010). "Friends with benefits: A social media-marketing handbook". San Francisco: No Starch Press.

[5]. Borges, B. (2009). "Marketing 2.0 Bridging the Gape between Seller and Buyer through Social Media Marketing" (First Edition ed.). Tucson, Arizona: Wheatmark.

[6]. Bucy, E.P. (2003). "The interactivity paradox: closer to the news but confused". In E.P. Bucy \& J.E. Newhagen (eds) Media Access Social and Psychological Dimensions of New Technology Use. Mahwah, NJ: Erlbaum, pp. 47-72.

[7]. Burmaster, A. (2009). Global faces and networked places. Retrieved from https://nielsen.com/nielsenwire/wpcontent/uploads/2009/03/nielsen_globalfaces_mar09.pdf

[8]. Cheung, C. M. K., M. K. O. Lee, \& D. R. Thadani. (2009). "The impact of positive electronic word-of- mouth on consumer online purchasing decision”. Visioning and Engineering the Knowledge Society. A Web Science Perspective, ed. M. D. Lytras et al. Lecture Notes in Computer Science 5736: 501-510.

[9]. Facebook. (2012). Facebook policies. Retrieved from https://developers.facebook.com/policy/

[10]. Facebook. (2011). Facebook statistics. Retrieved from http://www.facebook.com/press/info.php?statistics

[11]. Filho, L. M., and F. B. Tan. (2009). "User-generated content and consumer empowerment in the travel industry: A uses \& gratifications and dual-process conceptualization". Paper 28 presented at the Pacific Asia Conference on Information Systems (PACIS).

[12]. Fiore, A.M., Kim, J. \& Lee, H.H. (2005). "Effect of image interactivity technology on consumer responses toward the online retailer", Journal of Interactive Marketing, 19(3), pp. 38-53.

[13]. Fogg, B.J. (2003). "Persuasive Technology: Using Computers to Change What We Think and Do". Boston: Morgan Kaufmann.

[14]. Forman, C., A. Ghose, and B. Wiesenfeld. (2008). "Examining the relationship between reviews and sales: The role of reviewer identity disclosure in electronic markets", Information Systems Research 19 (3): 291-313.

[15]. Ghose, A., P. Ipeirotis, and B. Li. (2009). "The economic impact of user-generated content on the Internet: Combining text mining with demand estimation in the hotel industry". Retrieved from http://pages.stern.nyu.edu/ bakos/wise/papers/wise2009-p07_ paper.pdf

[16]. Gommans, M., Krishnan, K.S. \& Scheffold, K.B. (2001). "From brand loyalty to e-loyalty: A conceptual framework", Journal of Economic and Social Research, 3(1) 2001, pp.43-58

[17]. Gurau, C. (2008). "Integrated online marketing communication: implementation and management", Journal of Communication Management, vol. 12 no. 2, pp. 169-184 DOI 10.1108/13632540810881974

[18]. Hafele, N. (2011). "Social Media Marketing: Interaction, Trends \& Analytics", ICT 511 Fall, 51 (3): 1-6

[19]. Hart, C., Neil, D. and Ellis-Chadwick, F. (2000). "Retailer adoption of the internet - implications for retail marketing", European Journal of Marketing, vol. 34 no. 8, pp. 954-74.

[20]. Helmsley, S. (2000). "Keeping Custom," Marketing Week (UK), 23 (7): 39-42.

[21]. Hennig-thurau, T., K. P. Gwinner, G. Walsh, and D. D. Gremler. (2004). "Electronic word-of-mouth via consumer-opinion platforms: what motivates consumers to articulate themselves on the Internet?", Journal of Interactive Marketing 18 (1): 38-52.

[22]. Hill, S., Provost, F. \& Volinsky, C. (2006). "Network-Based Marketing: Identify likely adopters via consumer networks", Journal of Statistical Science, vol. 21, no.2, pp .256-276 DOI: 10.1214/088342306000000222

[23]. Hill, P.R., Moran, N. (2011). "Social marketing meets interactive media: lesson for advertising company", International Journal of Advertising, 30(5), pp. 815-838 DOI: 10.2501/IJA-30-5-815-838

[24]. Hoffman, D., Novak, T., \& Peralta, M. (1999). "Information Privacy in the Marketspace: Implications for the Commercial Uses of Anonymity on the Web", Information Society, 15 (2): 129-140.

[25]. Huang, P., Lurie, N.H. \& Mitra, S. (2009). "Searching for experience on the web: an empirical examination of consumer behavior for search and experience goods", Journal of Marketing, 73(2), pp. 55-69.

[26]. Kalyanaraman, S. \& Sundar, S.S. (2003). "The psychological appeal of personalized online content: an experimental investigation of customized web portals", Paper presented at the meeting of the International Communication Association, San diego, May.

[27]. Kaplan, A. M., and M. Haenlein. (2010). "Users of the world, unite! The challenges and opportunities of social media", Business Horizons 53:59-68.

[28]. Kollock, P. (1999). "The production of trust in online markets". In E.J. Lawler, M. Macy, S. Thyne \& H.A. Walker (eds) Advances in Group Processes, Vol. 16. Greenwich, CT: JAI Press.

[29]. Li, Hairong, Terry, D., \& Frank, B. (2002). "Impact of 3-D Advertising on Product Knowledge, Brand, Attitude, and Purchase Intention: The Mediating Role of Presence", Journal of Advertising, 31 (3), 59-67.

[30]. Liu, Yuping \& L.J. Shrum (2002). "What Is Interactivity and Is It Always Such a Good Thing? Implications of Definition, Person, 
and Situation for the Influence of Interactivity on Advertising Effectiveness,” Journal of Advertising, 31 (4), 53- 66.

[31]. Montgomery, A. L. (2001). "Applying quantitative marketing techniques to the Internet interfaces", 31(2) 90-108.

[32]. Murugesan, S. (2007). "Business uses of web 2.0: potential and prospects", Presented at Cutter Consortium, Business-IT Advisory Service, $10(1)$, pp. $1-28$.

[33]. Nielsen. (2011). "State of the media: the social media report", Nielsen Company. Retrieved from http://blog.nielsen.com/nielsenwire/social/

[34]. Ratnasingham, P. (1998). "Internet-based EDI trust and security, Information Management \& Computer Security", 6 (1): 33-40

[35]. Ray, A., Riley, E., Elliot, N., Corcoran, S., Greene, M., Parrish, M., O'Connell, J., \& Wise, J. (2011). "Now social media marketing gets tough: saturation, stagnation, and privacy concerns challenge social media marketers".

[36]. Riegner, C. (2007). "Word of mouth on the web: the impact of web 2.0 on consumer purchase decisions", Journal of Advertising Research, 47(4), pp. 437-447.

[37]. Roberts, R. R., and J. Kraynak. (2008). "Walk like a giant, sell like a madman". Hoboken,NJ: Wiley.

[38]. Sheth, J.N., Sharma, A. (2005). "International e-marketing: opportunities and issues, International Marketing Review", vol. 22 no. 6, 2005 pp. 611-622 DOI 10.1108/02651330510630249

[39]. Steinman, M.L., Hawkins, M. (2010). "When marketing through social media, legal risks can go viral", Intellectual Property \& Technology Law Journal, vol. 22 no.8, pp. 1-9.

[40]. Stephen, A. T., and J. Galak. (2009). "The complementary roles of traditional and social media in driving marketing performance". Retrieved from http://bear.warrington.ufl.edu/weitz/mar7786/Articles/social\%20 and\%20tradiitonal\%20media.pdf?

[41]. Steuer, J. (1992). "Defining virtual reality: dimensions determining telepresence", Journal of Communication, 42, 73-93.

[42]. Tanuri, I. (2010). "A literature review: Role of social media in contemporary marketing". Retrieved from http://agroovyweb.com/2010/03/11/university-of-chicago-and-my-literature- review-role-of-social- media-in-contemporarymarketing/

[43]. Universal McCann. (2008). "Power to the people social media tracker". Retrieved from http:// www.universalmccann.com/Assets/wave_3_20080403093750.pdf

[44]. Watson, R.P., Leyland, F.P., Berthon, P. and Zinkham, G. (2002). "U-commerce: expanding the universe of marketing", Journal of the Academy of Marketing Science, vol. 30 no. 4, pp. 333-47

[45]. Weinberg, T. (2009). "The new community rules: Marketing on the social Web". Sebastopol, CA: O"Reilly Media Inc.

[46]. Weiss, A.M., Lurie, N.H. \& Macinnis, d.J. (2008). "Listening to strangers: whose responses are valuable, how valuable are they, and why?", Journal of Marketing Research, 45(4), pp. 425-436.

[47]. Xiang, Z., and U. Gretzel. (2010). "Role of social media in online travel information search", Tourism Management 31:179-188. 